\title{
Correction to: Measurement Strategies for Evidence-Based Psychotherapy for Posttraumatic Stress Disorder Delivery: Trends and Associations with Patient-Reported Outcomes
}

\author{
Brian Shiner ${ }^{1,2,3}$. Christine Leonard Westgate ${ }^{1} \cdot$ Jiang Gui $^{2} \cdot$ Sarah Cornelius ${ }^{1}$. Shira Maguen ${ }^{5,6}$. \\ Bradley V. Watts ${ }^{2,4}$. Paula P. Schnurr ${ }^{2,3}$
}

Published online: 20 April 2020

(c) Springer Science+Business Media, LLC, part of Springer Nature 2020

\section{Correction to: \\ Administration and Policy in Mental Health and Mental Health Services Research (2020) 47:451-467 \\ https://doi.org/10.1007/s10488-019-01004-2}

The original version of this article unfortunately contained a mistake. The co-author name was incorrectly published with the middle initial in the author list.

The author name should be listed as "Shira Maguen" rather than as Shira E. Maguen.

It has been corrected in this correction.
Publisher's Note Springer Nature remains neutral with regard to jurisdictional claims in published maps and institutional affiliations.

The original article can be found online at https://doi.org/10.1007/ s10488-019-01004-2.

Brian Shiner

brian.shiner@va.gov

1 White River Junction VA Medical Center, 215 North Main Street, White River Junction, VT, USA

2 Geisel School of Medicine at Dartmouth, Hanover, NH, USA

3 National Center for PTSD Executive Division, White River Junction, VT, USA

4 VA Office of Systems Redesign and Improvement, Washington, DC, USA

5 San Francisco VA Medical Center, San Francisco, CA, USA

6 University of California, San Francisco, CA, USA 